\title{
Lagrange Multiplier Method for Drilling Oil Reservoir
}

\section{Vasant $P^{*}$, Maung MT, Min YW, Tun HM and Thant KZ}

${ }^{1}$ Department of Fundamental \& Applied Sciences, Faculty of Science \& Information Technology, Universiti Teknologi PETRONAS, Malaysia

${ }^{2}$ Department of Petroleum Engineering, Universiti Teknologi PETRONAS, Malaysia

*Corresponding author: Pandian Vasant, Department of Fundamental \& Applied Sciences, Faculty of Science \& Information Technology, Universiti Teknologi PETRONAS, Malaysia, Tel: 60103819267; E-mail: pvasant@gmail.com

Received date: May 09, 2017; Accepted date: June 10, 2017; Published date: June 17, 2017

Copyright: () 2017 Vasant P, et al. This is an open-access article distributed under the terms of the Creative Commons Attribution License, which permits unrestricted use, distribution, and reproduction in any medium, provided the original author and source are credited.

\section{Practical Use of the Concept in Petroleum Engineering}

Casing is one of the basic process in drilling the petroleum out of the reservoir. Steel is widely used in casing because of its durability and corrosion resistance. Since the petroleum business is at peak nowadays, one can observed many oil rigs on shore and off-shore throughout the world. Many theories are being used in petroleum exploration, extraction and production. One of them is Lagrange Multiplier method. In mathematical optimization, the method of Lagrange multipliers (named after Joseph Louis Lagrange $(2,3)$ ) is a strategy for finding the local maxima and minima of an objective function subject to equality constraints.

Lagrange multiplier is used when some constraints are faced in the working process. An example of the use of Lagrange Multiplier in casing instalment in an oil rig. The use of the theory is presented from the economic aspect of view.

In this problem, a steel casing is to be installed. Let's say the labour cost for the instalment is $20 \$$ per hour. The price of the steel is $2000 \$$ per ton. The manager of the project is provided with the budget of $20,000 \$$ and the cost of the whole project has to be satisfied with the provided budget. Now this problem is dealing with the constraints (Refer to Figure 1).

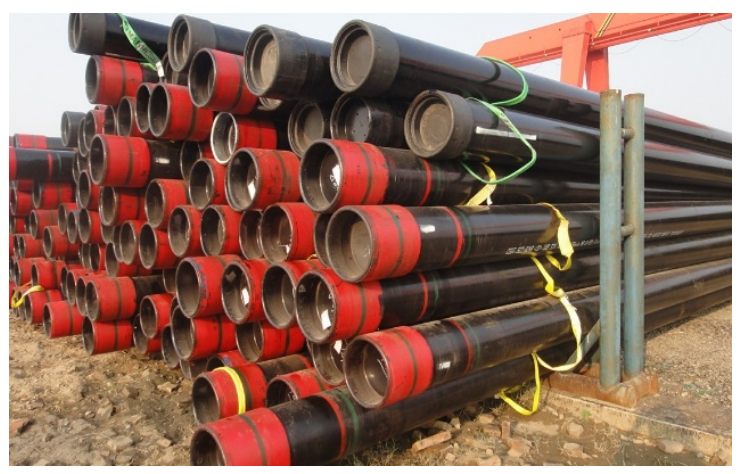

Figure 1: Steel casing [1].

In this case, Lagrange Multiplier is found to be very useful. Let the hours of labour and tons of steel be " $h$ " and "s" respectively. The objective function is given in eqn. (1).

The cost of labour and the tons of steel have to fall within the provided budget. So the cost of labour become $20 \mathrm{~h}$ and the cost of steel required become 2000s.

So the constraint function is given in eqn. (2).

$G(h, s)=20 h+2000 s=20,000$
By the using the Lagrange multiplier, one have to partially differentiate both equations with respect to $h$ and s. Since only one constraint is given here, therefore only one parameter ' $\lambda$ ' has to be considered as in eqn. (3).

$$
\mathrm{h}=200 \mathrm{~s}
$$

Substituting $\mathrm{h}=200 \mathrm{~s}$ in constraint eqn. (2), the value of ' $\mathrm{s}$ ' can be determined, which is " $s=10 / 3$ tons" (tons of steels required).

Substitute $s=10 / 3$ into $h=200 s$, this gives $h=2000 / 3$ hours. So the manager finally figure out how to make it happen with the provided budget in the decision making process. This is the use of the concept of Lagrange Multiplier in Petroleum Engineering business in economic point of view.

Next, there is another problem concerning with the Petroleum Geoscience. Let's say the function of the temperature of the central earth core is calculated as follow; the earth is considered as a sphere so one can use the sphere equation as in Figure 2 [3].

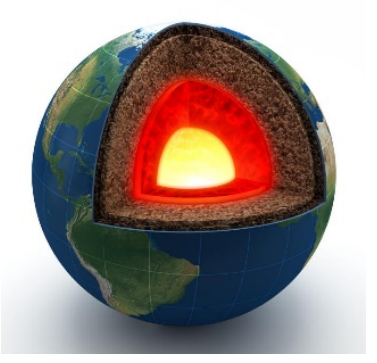

Figure 2: Temperature of the Earth Core [2].

The objective function is given in equation

$$
\mathrm{F}(\mathrm{x}, \mathrm{y}, \mathrm{z})=\mathrm{x}^{2}+\mathrm{y}^{2}+\mathrm{z}^{2}
$$

Since the earth is a bit flat on the North Pole, therefore there are two constraints, one from North Pole and the other from South Pole. So the diameters of the central core is given in eqns. (5) and (6).

$$
\begin{aligned}
& G(x, y, z)=x+2 y+3 z=3000 \text { miles } \\
& H(x, y, z)=x+y+z=4000 \text { miles }
\end{aligned}
$$

The problem is to find the maximum temperature along the diameter. By the nature of the problem, there are two constraints and so there are two parameters, ' $\lambda$ ' and ' $\mu$ ' to be considered in this case. One can start by partially differentiating the three eqns. (4)-(6).

By satisfying those equations, one can find the value for the $\lambda=-500$ and $\mu=13000 / 6$. Substituting those two in the above equations will give the values of $x=833.333, y=291.67$, and $z=333.33$. Substituting these $x$, 
Citation: Vasant P, Maung MT, Min YW, Tun HM, Thant KZ (2017) Lagrange Multiplier Method for Drilling Oil Reservoir. Ind Eng Manage 6: 217. doi:10.4172/2169-0316.1000217

Page 2 of 2

$\mathrm{y}$, and $\mathrm{z}$ in the main objective function as in eqn. (4), the desired temperature can be obtained as $890625^{\circ} \mathrm{F}$.

The use of the Lagrange multiplier is important in every engineering field, in daily lives, in economics and it is so important that it still hold a position.

\section{References}

1. https://www.khanacademy.org/

2. Anton H, Bivens I, Davis S (2010) Calculus Early Transcendental 9th edition. John Wiley \& Sons Inc USA.

3. Johnston EH, Mathews JC (2002) Calculus. Addison and Wesley, USA. 